\title{
ESCRIBIR PARA RECORDAR
}

Sobre Marcelo Britos. A dónde van los caballos cuando mueren. Buenos Aires: Aurelia Rivera, 2015. 180 pp.

Pablo Cinquini

UNR

Antes de ser publicada en Argentina, $A$ dónde van los caballos cuando mueren ha sido consagrada con el primer puesto en el Certamen Internacional de Literatura Sor Juana Inés de la Cruz 2013 y publicada en México. Además, ha sido traducida para una edición italiana en 2015. Con la publicación de la editorial porteña Aurelia Rivera a fines del año pasado, la novela de Marcelo Britos ha podido desembarcar en Argentina, trazando un recorrido de sentido prácticamente inverso al que realiza su personaje principal cuando intenta huir de este país aún en construcción.

Mariano de Orma, un médico al servicio del ejército argentino, abandona el campamento de Tuyutí en la Guerra contra el Paraguay tratando de escapar de la atrocidad del enfrentamiento, aferrándose a lo único que encuentra de humano entre tanta masacre: la promesa de buscar, para un soldado que muere entre sus manos, el perdón de su cuñada y sus sobrinos. Sin embargo, el protagonismo de la historia quizás no esté en el personaje, sino más allá de él, a tal punto que, en la primera de las tres partes que componen el libro, son tres los personajes que comparten camino huyendo de la guerra pero podrían ser considerados uno solo unidos en su calidad de desertores. La renuncia es la condición que 
acompañará a De Orma desde su huida hasta el final de sus días: renuncia a ser parte de la masacre, aún sabiendo que eso implica una traición, renuncia a sus convicciones cuando ve que el perdón que busca para el soldado muerto no tiene importancia para nadie más que para él, renuncia a sus esperanzas cuando descubre que su mujer se ha marchado al enterarse de su deserción. Cuando todas sus convicciones se reducen a polvo y su vida parece convertirse en un sinsentido, curar es lo único que le devuelve un poco de humanidad y el médico acepta con resignación un destino que parece estarle asignado: curar a los heridos de los enfrentamientos impulsados desde adentro de las fronteras de su civilización.

Hablar de "frontera" y de "civilización" no es azaroso porque la novela de Britos tematiza la "cuestión de indios": guaraníes y comechingones pero fundamentalmente ranqueles, yaganes, onas, víctimas del ataque del ejército o de cazadores a sueldo de grandes estancieros de la patagonia, son retratados en el recorrido del médico por gran parte de un mapa argentino que aún no terminaba de dibujarse $y$, para cuyo trazado, los indios constituían un obstáculo. Las tribus originarias parecen ser las portadoras de la verdadera civilidad frente a la brutalidad del hombre blanco del mismo modo que el pueblo paraguayo cuando es descripto defendiendo su soberanía frente a la devastación de los ejércitos invasores lanzándose en balsas contra los acorazados de guerra o dibujando barba en el rostro de los niños para que pasen por adultos frente al enemigo. De esta novela, se ha dicho que es una reescritura del Martín Fierro ya que, como el personaje de José Hernández, el de Britos deserta y vuelve a la civilización en busca de su familia. Hay, además de De Orma, otros personajes que tienen una historia de vida similar a la de Fierro. Sin embargo, también es posible una lectura del texto desde Una excursión a los indios ranqueles: al igual que la obra de 
Lucio V. Mansilla, el texto de Britos se interna en la otredad y demuestra el artificio que se encuentra tras el par civilización/barbarie.

A raíz de la deserción que tiene lugar en las primeras páginas, De Orma recorre medio país buscando el lugar indicado por el soldado muerto. Al llegar a Buenos Aires, decide entregarse nuevamente al ejército y, luego de su castigo, se le encomienda asistir a los enfermos de cólera de la epidemia de 1867 antes de ser enviado nuevamente a Paraguay. Al finalizar la guerra, se le asigna un puesto en la comisaría de la recién fundada Rawson. A partir de allí, la novela recorre toda la patagonia. La descripción de los lugares, las personas y los acontecimientos de toda la novela está elaborada sobre la base de información extraída de archivos históricos: las batallas de la guerra, los levantamientos federales, la epidemia, las matanzas ranquelinas, la inmigración, la colonización galesa de Chubut; todo se encuentra perfectamente ajustado a los testimonios históricos, podemos incluso leer un fragmento del diario de viaje del gobernador Luis Fontana de la expedición de los Rifleros del Chubut en los territorios cercanos a la cordillera de los Andes. Por momentos, el discurso de la historia queda integrado en la novela; otras veces, nos traslada a otro plano, sacándonos de la trama, como si el autor quisiera evitar ceder a la ficción para no trivializar la importancia de los hechos.

El conflicto de la novela, más allá de la inconformidad del médico con su entorno social -un entorno social que, por otra parte, es prácticamente inexistente ya que sólo un puñado de personajes tiene incidencia en la vida del médico-, se plantea entre los acontecimientos históricos y el concepto de humanidad. Las relaciones personales de Mariano de Orma, que toman preponderancia por momentos, en la totalidad de su vida, parecen reducirse a anécdotas. El médico se convierte 
en un individuo enfrentado con el relato histórico oficial, un símbolo de la voz de los vencidos de todo un período de la historia argentina. Con esta novela, Britos continúa la línea de trabajo iniciada con el volumen de cuentos El último azul de la noche (El Ombú Bonsai, 2013), un revisionismo que, esta vez, no se acota, como en aquel caso, a acontecimientos particulares, sino que, de manera más ambiciosa, abarca todo el período de Organización Nacional.

Los acontecimientos históricos, como todo hecho social, sólo pueden ser aprehendidos y transmitidos por medio de los relatos que de ellos se realicen. El tratamiento literario de la historia puede jugar un rol fundamental en su debate y $A$ dónde van los caballos cuando mueren nos permite adentrarnos en la segunda mitad del siglo XIX para apropiarnos, críticamente y a la distancia, del espíritu que dominó toda una época de la historia argentina, un espíritu que, como lo ilustran las palabras de un cacique mapuche pero que puede ser extendido a cualquier otro pueblo originario, pretendía "terminar con esa sangre y esa lengua como si así pudieran expulsar a Nguenechén para traer a otro" (150). No sabremos nunca dónde van los caballos cuando mueren, tampoco dónde van los hombres; sólo sabemos que después de muertos sólo queda su recuerdo. La rememoración es una posibilidad de devolverle entidad a esos vencidos y olvidados y, con esta rememoración ficticia, Britos demuestra que la historia puede continuar siendo interpretada mediante la escritura. 